\title{
Effects of Praziquantel Treatment on the Levels of Total Bile Acids and the Basement Membrane Formation in Schistosomiasis: Correlations with the Severity of the Disease
}

\author{
El-Shahat A. Toson ${ }^{a}$ and Kadry Gad ${ }^{b}$ \\ ${ }^{a}$ Chemistry Dep. (Biochemistry Division), Faculty of Science \\ (Damietta) and ${ }^{\mathrm{b}}$ Emergency Hospital, Faculty of Medicine, \\ Mansoura University, Mansoura, Egypt
}

\begin{abstract}
The pathological effects of schistosomiasis are due to immune responses of the host to the eggs of the parasite leading to intestinal and hepatic granulomatous disease and hepatic fibrosis. Therefore, biochemical serum analyses concomitant with haematological, microscopical, ultrasonographical and clinical examinations were performed on 45 Schistosoma infested patients and on 15 matched healthy controls. According to the development of the liver damage, as was reflected by Child Pugh's score, the patients were classified into 3 groups, containing 15 patients' each. The patients of group I were suffering from simple intestinal bilharzial infestation and those of the group II and group III were bilharzially infested patients with Child A and Child B, respectively. The patients were treated with triple doses of praziquantel (PZQ) and the levels of total bile acids, laminin P1 (LP1), liver function tests (LFTs) and blood picture were evaluated before and after 6 months of the treatment. Also, the presence of schistosomal antibodies, its ova in stool or positivity of rectal snip for such ova, before treatment, were used as diagnostic tools of bilharzial infestation. At the same time, the clinical and ultrasonographical parameters were evaluated and their correlations with the previous parameters were calculated. It was found that, Schistosoma infestation caused damage to the liver with subsequent elevations in the mean values of total bile acids (TBA), the basement membrane component (LP1) and the parameters of LFTs due to presence of periporal fibrosis. After PZQ's treatment, the levels of the previous parameters were retuned back into levels reaching those of the control group. In conclusion, PZQ treatment can cause spontaneous resolution of liver fibrosis. In addition, the levels of total bile acids and LP1 can reflect the severity of liver damage and the susceptibility to PZQ's treatment. Moreover, one can not neglect the role of LP1 in the regulation of inflammation in schistosomiasis.
\end{abstract}

Key words: Schistosomiasis, praziquantel, laminin P1 and rectal snip.

\section{INTRODUCTION}

Hepatic involvement in schistosomiasis mansoni results from the host immune response to disseminated eggs that were laid in the portal venous system and become trapped in hepatic sinusoids. This is because the eggs reaching the liver are too large to reach the sinusoidal 
plexus and accumulate in presinusoidal venules within the portal triads, especially in the left lobe, producing granulomatous lesions that are followed by fibrosis ${ }^{(1)}$. Therefore, hepatic fibrosis is considered as the main morbid sequala of schistosomiasis mansoni, which participates portal hypertension and bleeding oesophageal varices ${ }^{(2)}$.

Basement membranes (BMs) are thin sheets of specialized extracellular matrix (ECM) which lay beneath epithelial and endothelial cells and surround other cell types. Besides providing tissue boundaries and structural support, BMs influence cell proliferation, differentiation, and migration. These membranes are predominantly composed of laminins, type IV collagen, heparan sulphate proteoglycans, and entactin/nidogen ${ }^{(3)}$. Although fragments of BM components have been detected in biological fluids in association with various inflammatory diseases, it is unknown whether its components are active in the regulation of inflammation or not ${ }^{(4,5)}$.

As regards to schistosomiasis mansoni, previous studies showed that the schistosomules elaborate an antiinflammatory and immunomodulatory factors which may help the parasite to evade the host immune response ${ }^{(6,7)}$. In addition, chronic schistosomiasis is associated with impaired cellmediated immune response ${ }^{(8)}$. The $\mathrm{H}_{2} \mathrm{O}_{2}$ peroxidase system, which is the cornerstone of host defense and associated with inflammation, is activated in close contact with parasite eggs. Moreover, hepatocytes undergo oxidative stress in the entire organ, which induces decrease of the liver antioxidant defences and deposition of $\mathrm{ECM}^{(9)}$ with subsequent liver derangement. Also, reports indicated that the redox cascade involved in maintenance of cell haemostasis, as well as in the parasitic protection against reactive oxygen species produced by the host is known to influence the pro-oxidant/antioxidant balance in both host and parasite with a final effects on LFTs ${ }^{(\mathbf{1 0})}$. As a result, portal hypertension, which is defined as a pathological increase in the pressure of the portal venous system, was increased.

One of the most common causes of portal hypertension is cirrhosis which may be due to basement membrane formation, including LP1 and collagens deposition. This type of hypertension may also be present in the absence of cirrhosis, a condition referred to as "noncirrhotic portal hypertension" which can be divided into prehepatic, intrahepatic (presinusoidal, sinusoidal, postsinusoidal and post-hepatic causes). Schistosomiasis is one of the presinusoidal causes of noncirrhotic portal hypertension ${ }^{(11-13)}$.

Liver performs many essential functions for the body, including absorption of fat in the diet ${ }^{(\mathbf{1 4 )}}$. Total bile acids (TBA) are essential components in absorption of such fats. These acids are principally synthesized by the liver and are strongly correlated with the development of hepatic fibrosis and portal hypertension. These render them to be used as indicators of liver damage $^{(\mathbf{1 5})}$. Cholesterol, derived from circulating lipoproteins or from de novo synthesis in the liver, is converted to bile acids through 
chemical modifications initiated by $7 \alpha$-hydroxylation. After conjugation to taurine or glycine, bile acids are actively secreted from the hepatocytes, together with free cholesterol and phospholipids, and are retained in the gallbladder during fasting. In response to a meal, cholecystokinin is released from the gut, resulting in the release of concentrated bile to the duodenum, where the detergent bile acids promote the absorption of dietary fat. Passive uptake of some bile acids occurs along the small intestine, but the major fraction is taken up by active transport in the terminal ileum. Bile acids are then transported in the portal vein back to the liver, where they are actively taken up in hepatocytes and resecreted into bile, thereby completing their enterohepatic circulation $^{(\mathbf{1 6})}$.

Hepatic schistosomiasis induces a compensatory hypertrophy of the hepatic artery, with increased sinusoidal pressure resulting in alterations of hepatic function ${ }^{(17)}$. Also, there are few published papers dealing with hepatic regeneration in schistosomiasis inspite of the importance of that disease ${ }^{(\mathbf{1 8})}$. Therefore, researchers have been stimulated to identify antifibrotic therapies. However, the most effective therapy for treating hepatic fibrosis to date is still to remove the causative agent. Also, they have been stimulated to identify antifibrotic therapies and to develop non-invasive markers to assess liver fibrosis as one of the strategies to follow-up the fibrotic and the antifibrotic changes in the liver ${ }^{(\mathbf{1 9})}$. For these reasons, formation of basement membrane, as was reflected by the pepsin-resistant fragment LP1 and the levels of TBA were used to evaluate the treatment and the regenerative effects of $\mathrm{PZQ}$ on the liver in schistosomiasis.

\section{SUBJECTS \& METHODS}

The present study involved 45 Schistosoma mansoni infested patients in addition to 15 healthy individuals with matched age and sex which were used as a control group. The patients were classified into 3 groups according to the severity of liver damage using Child Pugh's score. Group I contained 15 patients with simple intestinal bilharzial infestation, group II consisted of 15 bilharzially infested patients with Child A and group III contained 15 bilharzia infested patients but with Child B. The patients were treated with triple doses of PZQ (40 $\mathrm{mg} / \mathrm{kg}$ body weight).

All subjects were subjected to full clinical assessment to exclude other parasitic infections. Neither the patients nor the control groups had evidence of any other diseases nor any being treated with drugs known to affect liver function tests, bile acids or the parameters of the blood picture. The biochemical examinations were performed before and after 6 months of the last treatment dose.

Schistosoma mansoni infestation was detected by positive stool analysis using the direct smear technique and Kato thick smear ${ }^{(20)}$, sigmoidoscopy and rectal snips were performed for the negative stool samples. Also, indirect haemagglutination assay was performed to confirm bilharzial infestation using Fumouza 
Diagnostics kit (Le Malesherbes110-114, rue Victor Hugo, 92300 LEVALLOIS-PERRET, FRANCE). Abdominal ultrasnography was done for diagnosis of periportal fibrosis and measurement of the diameters of splenic and portal veins. Serum TBA and LP1 were determined by the method of Block and Watkins (21) and by radio-immunoassays (RIA) using the kit produced by Behringwerke, Marburg (Germany) associated with Hochest, respectively. In addition, parameters of LFTs were done which included determination of total serum bilirubin value by the colorimetric technique of Bartles and Bohmer ${ }^{(22)}$, alkaline phosphatases (ALP) by the method of Kind and $\mathrm{King}^{(23)}$, alanine aminotranseferase (ALT) and aspartate aminotranseferase (AST) by the method of Reitman and Frankel ${ }^{(24)}$ and prothrombin time was determined by using the DiaMed's kit (DiaMed, 1785 Cressier, Switzerland). Statistical analysis

The results were analyzed using instate software, version 2.03 (Graphpad, USA). The probability level signifying the variable grades of statistical significance are indicated as follow: $\mathrm{P}<0.05$, significant and $\mathrm{P}<0.001$ is highly significant. Also, the linear regression analysis was used to describe the relationships between the studied parameters. For comparison of the investigated parameters before with after treatment paired student $t$ " $t$ " test was used. Paried student " $\mathrm{t}$ ' test was used to compare the parameters before and after treatment.

\section{RESULTS}

Table 1 showed the results of the laboratory, clinical, ultrasonographical and the endoscopical data of Schistosoma mansoni infested patients before PZQ's treatment. This table showed that, Schistosoma antibodies were positive in sera of all patients. Simultaneously, the laboratory data showed that Schistosoma ova in stool were increased with the severity of the liver damage. Clinically, the hepatomegally, splenomegally and the presence of ascites were increased with the increase in the severity of the disease. In addition, the ultrasonographic data showed that, the diameters of the splenic and portal veins were increased from simple intestinal into those with child B. Moreover, the degree of liver periportal fibrosis was increased with the increase in the size of the spleen and the shrinkage in the liver. At the same time, the number and the degree of oesophageal varices were increased, especially in patients with child A and child B using upper gastrointestinal endoscopy.

Table 2 showed that before PZQ's treatment, the mean serum levels of TBA, LP1, bilirubin and the activities of ALP as well as those of liver transaminases (ALT and AST) were significantly higher in sera of all Schistosoma mansoni infested patients compared with those of the control group $(\mathrm{P}<0.05)$. On the other hand, the mean serum albumin level was significantly decreased compared with that of the normal control $(\mathrm{P}<$ 0.0001). The same table showed that, such treatment repaired many of the parameters of LFTs in addition to 
reduction in the mean serum levels of both LP1 and TBA compared with their values in the non-treated group (Table 2).

When the patients were classified according to the Child classification, it was shown that these parameters were changed with the severity of the disease. The increase in mean levels of both LP1 and TBA and in the mean activity of ALP and the decrease in serum albumin mean levels and in the prothrombin activities were repaired after treatment, especially in the earlier stages of the disease (Tables 3 and 4).

Table 1: Laboratory, clinical, ultrasonographical and endoscopical data of bilharzia infested patients.

\begin{tabular}{|c|c|c|c|}
\hline Parameters & Simple & Child A & Child B \\
\hline \multicolumn{4}{|l|}{ Laboratory Data: } \\
\hline i- Schisto. eggs positive & $4 / 15$ & $6 / 15$ & $11 / 15$ \\
\hline ii- Schist. antibodies positive & $15 / 15$ & $15 / 15$ & $15 / 15$ \\
\hline \multicolumn{4}{|l|}{ Clinical Data: } \\
\hline i- Hepatomegally & $0 / 15$ & $61 / 15$ & $11 / 15$ \\
\hline .ii- Splenomegally & $0 / 15$ & $15 / 15$ & $15 / 15$ \\
\hline .iii- Ascites & $\mathbf{0} / \mathbf{1 5}$ & $\mathbf{0} / \mathbf{1 5}$ & $8 / 15$ \\
\hline \multicolumn{4}{|l|}{ Ultrasonographical Data: } \\
\hline i- Splenic vein diameter ${ }^{\mathrm{s}}$ & $1.12 \pm 0.15$ & $1.26 \pm 0.12^{*}$ & $1.24 \pm 0.09 !$ \\
\hline ii- Portal vein diameter & $1.15 \pm 0.14$ & $1.31 \pm 0.19^{*}$ & $1.56 \pm 0.29^{! !}$ \\
\hline iii- Size of the liver & Normal & Enlarged $(15 / 15)$ & Shrinking $(15 / 15)$ \\
\hline iv- Size of the spleen & Normal & Enlarged $(15 / 15)$ & Enlarged $(15 / 15)$ \\
\hline $\begin{array}{lll}\mathrm{v}-. . \text { Presence } & \text { of } & \text { Periportal } \\
\text {....fibrosis } & & \\
\end{array}$ & $0 / 15$ & $\begin{array}{c}\text { GI }(7 / 15) \& \text { GII } \\
(5 / 15)\end{array}$ & $\begin{array}{c}\text { GII }(8 / 15) \& \text { GII } \\
(7 / 15)\end{array}$ \\
\hline \multicolumn{4}{|l|}{ Endoscopical Data: } \\
\hline i-..Oesophageal.varices & No varices & $\operatorname{GII}(7 / 15)$ & $\mathrm{GI}(5 / 15) \& \mathrm{GII}(8 / 15)$, \\
\hline ii-. Rectal snip positive & $11 / 15$ & $11 / 15$ & $10 / 15$ \\
\hline
\end{tabular}

GI, GII and GIII indicate grade I, grade II and grade III, respectively. $a=$ Values were expressed as mean \pm standard deviations (SD), ${ }^{*}=P<0.05$ (significant) when they were compared with their corresponding values of simple intestinal Schistosomiasis. !! $=P<0.001$ is highly significant when compared with their corresponding values of patient with Child $B$. Values between the parentheses indicate the number compared to the total number of the group in each cases. 
Correlations between serum TBA and LP1 with the parameters of LFTs and blood picture in all $S$. mansoni infested patients:

The individual results of serum Lp1 were positively correlated with those of TBA $(\mathrm{r}=0.17, \quad \mathrm{P}<0.34$, insignificant $)$ bilirubin $(\mathrm{r}=0.4$, $\mathrm{P}<0.0008)$, AST $(\mathrm{r}=0.41, \mathrm{P}<0.0004)$, ALT $(r=0.44, P<0.0002)$, ALP $(r=$ $0.46, \mathrm{P}<0.0004)$ and with those of the eosinophillic counts $\quad(\mathrm{r}=0.41$, $\mathrm{P}<0.0025)$. Also, the individual values of TBA were positively correlated (significant) with the esinophilic count $(\mathrm{r}=0.36, \mathrm{P}<0.034)$. On the other hand, its individual results were negatively correlated with those of albumin $(r=-$ 0.46, $\quad \mathrm{P}<0.0001)$, prothrombin activities $(\mathrm{r}=-0.63, \mathrm{P}<0.0001)$ and with those of haemoglobin $(r=-0.33$, $\mathrm{P}<0.0063)$.

Table 2: The mean serum levels of total bile acids, laminin P1 and the parameters of LFTs in sera of all patients infested with Schistosoma mansoni before and after treatment with praziquantel compared with those of the control group.

\begin{tabular}{|c|c|c|c|}
\hline $\begin{array}{ll}\text { Parameters } & \text { Group } \\
\end{array}$ & $\begin{array}{l}\text { Control }^{\mathbf{a}} \\
(\mathbf{M} \pm \mathrm{SD})(\mathrm{n})\end{array}$ & $\begin{array}{l}\text { Before Treatment }^{\mathbf{a}} \\
\mathbf{M} \pm \text { SD (n) }\end{array}$ & $\begin{array}{l}\text { After Treatment }^{\mathbf{a}} \\
\mathbf{M} \pm \mathrm{SD} \text { (n) }\end{array}$ \\
\hline Bile acids $(\mu$ Mole $/ L)$ & $8.3 \pm 4.2 \quad(15)$ & $15.2 \pm 7.3^{!}$ & $9.4 \pm 4.4^{* *}$ \\
\hline Laminin P1 $(\mathrm{IU} / \mathrm{ml})$ & $1.49 \pm 0.35(15)$ & $2.50 \pm 0.6^{! !}$ & $1.50 \pm 0.4^{* *}(42)$ \\
\hline Bilirubin $(\mathrm{mg} / \mathrm{dl})$ & $0.6 \pm 0.15 \quad(15)$ & $0.85 \pm 0.25^{! !}(44)$ & $0.78 \pm 0.23$ \\
\hline Albumin $(\mathrm{mg} / \mathrm{dl})$ & $4.7 \pm 0.5$ & $3.90 \pm 0.70 ! !(44)$ & $4.1 \pm 0.55$ \\
\hline $\operatorname{ALT}(I U / m l)$ & $23.8 \pm 5.2$ & $35.0 \pm 9.5^{! !}$ & $36 \pm 13.4$ \\
\hline AST (IU/ml) & $20.7 \pm 6.1 \quad(15)$ & $34.0 \pm 6.7^{! !}$ & $34 \pm 9.4$ \\
\hline $\operatorname{ALP}($ K.A.Us) & $4.9 \pm 1.8$ & $9.40 \pm 5.0^{! !}$ & $6.0 \pm 2.5^{* *}$ \\
\hline Prothrombin (\%) & $91 \pm 5.1$ & $77.3 \pm 11^{! !}$ & $88.2 \pm 8.9^{* *}$ \\
\hline
\end{tabular}

${ }^{a}$ Values were expressed as mean \pm standard deviations (SD), ! = significant and !! = highly significant when they were compared with their corresponding values of the control. $*=P<0.05$ is significant and $* *=P<0.001$ is highly significant when they were compared with their corresponding values before treatment. Also, Values between the parentheses indicate the number in each case. 
Table 3: The mean serum levels of total bile acids, laminin P1 and the parameters of LFTs in sera of patients with simple intestinal bilharziasis, patients with Child A and patients with Child B before after praziquantel's treatment compared with those after its treatment.

\begin{tabular}{|l|c|c|c|c|c|}
\hline Proup & $\begin{array}{c}\text { Albumin }^{\mathbf{a}} \\
(\mathbf{m g} / \mathbf{d l})\end{array}$ & $\begin{array}{c}\text { Bilirubin }^{\mathbf{a}} \\
(\mathbf{g} \cdot \mathbf{\%})\end{array}$ & $\begin{array}{c}\mathbf{A S T}^{\mathbf{a}} \\
(\mathbf{I U} / \mathbf{m l})\end{array}$ & $\begin{array}{c}\mathbf{A L T}^{\mathbf{a}} \\
(\mathbf{I U} / \mathbf{m l})\end{array}$ & $\begin{array}{c}\mathbf{A L P}^{\mathbf{a}} \\
(\mathbf{K . A . U s})\end{array}$ \\
\hline Simple (Before) & $4.65 \pm 0.36$ & $0.6 \pm 0.17$ & $30 \pm 7.0$ & $28 \pm 8.1$ & $7.5 \pm 2.3$ \\
& $(15)$ & $(15)$ & $(15)$ & $(15)$ & $(15)$ \\
\hline Simple (After) & $4.65 \pm 0.25$ & $0.53 \pm 0.12$ & $28 \pm 3.2$ & $28 \pm 5.3$ & $4.9 \pm 1.2$ \\
& $(15)$ & $(15)$ & $(15)$ & $(15)$ & $(15)^{* *}$ \\
\hline Child A (Before) & $3.75 \pm 0.38$ & $0.90 \pm 0.16$ & $35 \pm 4.1$ & $35 \pm 6.6$ & $11.6 \pm 6.1$ \\
& $(14)$ & $(15)$ & $(14)$ & $(15)$ & $(15)$ \\
\hline Child A (After) & $4.1 \pm 0.43$ & $0.89 \pm 0.17$ & $35.0 \pm 5.0$ & $34.0 \pm 8.5$ & $5.2 \pm 1.2$ \\
& $(15)^{*}$ & $(15)$ & $(15)$ & $(15)$ & $(15)^{* *}$ \\
\hline Child B (Before) & $3.25 \pm 0.30$ & $1.1 \pm 0.13$ & $38 \pm 5.8$ & $42 \pm 7.1$ & $15.6 \pm 5.1$ \\
& $(15)$ & $(15)$ & $(15)$ & $(15)$ & $(15)$ \\
\hline Child B (After) & $3.75 \pm 0.40$ & $0.90 \pm 0.18$ & $40.8 \pm 12$ & $46 \pm 15$ & $8.0 \pm 3.1$ \\
& $(15)^{* *}$ & $(15)^{* *}$ & $(15)$ & $(15)$ & $(15)^{* *}$ \\
\hline
\end{tabular}

${ }^{a}$ Values were expressed as mean \pm standard deviations (SD), $*=P<0.05$ is significant and... $* *=P<0.001$ is highly significant when compared with those before treatment. Values between the parentheses indicate the number in each case

Table 4:The mean serum levels of laminin P1, total bile acids and prothrombin activities of patients with simple intestinal bilharziasis, patients with Child A and patients with Child B before compared with those after praziquantel`s treatment.

\begin{tabular}{|l|c|c|c|}
\hline Group & $\begin{array}{c}\text { Laminin P1 } \\
(I U / m)\end{array}$ & $\begin{array}{c}\text { Bile acids } \\
(\mu M o l e / L)\end{array}$ & $\begin{array}{c}\text { Prothrombin } \\
(\%)\end{array}$ \\
\hline Simple (Before) & $2.36 \pm 0.52(11)$ & $15.0 \pm 7.3(11)$ & $89.4 \pm 4.7(15)$ \\
\hline Simple (After) & $1.5 \pm 0.36^{* *}(15)$ & $9.9 \pm 4.8^{*}(10)$ & $96.0 \pm 5.4(15)$ \\
\hline Child A (Before) & $2.4 \pm 0.70(15)$ & $20.1 \pm 10(8)$ & $75.6 \pm 6.3(15)$ \\
\hline Child A (After) & $1.45 \pm 0.46^{* *}(15)$ & $6.8 \pm 3.6^{* *}(8)$ & $84.0 \pm 5.3^{* *}(15)$ \\
\hline Child B (Before) & $2.9 \pm 0.37(14)$ & $9.9 \pm 5.2(8)$ & $66.0 \pm 5.1(15)$ \\
\hline Child B (After) & $1.47 \pm 0.42^{* *}(15)$ & $11.4 \pm 5.2(8)$ & $86 \pm 9.3^{* *}(15)$ \\
\hline
\end{tabular}

${ }^{a}$ Values were expressed as mean \pm standard deviations (SD), ${ }^{*}=P<0.05$ is significant and $* *=P<0.001$ is highly significant . Values between the parentheses indicate the number in each case. 
Table 5: The mean values of haemoglobin, counts of white blood cells (WBCs) as well as those of eosinophils \% in the blood of Schistosoma....mansoni infested patients before....and...after treatment...compared with those of the control group.

\begin{tabular}{|c|c|c|c|}
\hline Parameters & $\begin{array}{c}\text { Haemoglobin } \\
(\mathrm{g} . \%)\end{array}$ & $\begin{array}{c}\text { WBCs } \\
\left(\times 10^{3} / \mathrm{cmm}\right)\end{array}$ & $\begin{array}{c}\text { Eosinophils } \\
(\%)\end{array}$ \\
\hline Simple intestinal (Before) & $13.4 \pm 0.9(14)$ & $4.9 \pm 1.2(15)$ & $3.6 \pm 1.4(11)$ \\
\hline Simple intestinal (After) & $14.0 \pm 0.75^{*}(14)$ & $4.1 \pm 0.5^{*}(15)$ & $0.5 \pm 0.3^{* *}(14)$ \\
\hline Child A (Before) & $11.9 \pm 0.9(14)$ & $4.9 \pm 0.37(14)$ & $3.1 \pm 1.1(14)$ \\
\hline Child A (After) & $12.0 \pm 1.0^{*}(14)$ & $3.6 \pm 0.7^{* *}(14)$ & $0.7 \pm 0.3^{* *}(14)$ \\
\hline Child B (Before) & $11.9 \pm 0.7(14)$ & $3.4 \pm 0.55(14)$ & $1.75 \pm 0.8(14)$ \\
\hline Child B (After) & $11.7 \pm 0.9(14)$ & $3.5 \pm 0.6(14)$ & $0.93 \pm 0.4^{* *}(14)$ \\
\hline Total (Before) & $12.3 \pm 1.1(42)$ & $4.1 \pm 1.0(43)$ & $2.9 \pm 1.4(39)$ \\
\hline Total (After) & $12.6 \pm 1.3(42)$ & $3.75 \pm 0.7(43)$ & $0.64 \pm 0.3(39)$ \\
\hline
\end{tabular}

${ }^{a}$ Values were expressed as mean values \pm standard deviations $(S D), *=P<0.05$ (significant...and $* *=P<0.001$ is highly significant. Values between the parentheses indicate the range in each case.

Table (6): Correlations between serum TBA and LP1 with the parameters of LFTs, the diameters of Portal and Splenic veins and some of the blood picture indices in all S. mansoni infested patients

\begin{tabular}{|l|c|c|c|c|}
\hline \multirow{2}{*}{ Parameters } & \multicolumn{2}{|c|}{ Laminin P1 } & \multicolumn{2}{c|}{ Total bile acids } \\
\cline { 2 - 5 } & $R$ & $P$ & $r$ & $P$ \\
\hline Bile acids & 0.17 & 0.34 & - & - \\
\hline Bilirubin & 0.4 & 0.0008 & 0.13 & 0.42 \\
\hline Albumin & -0.46 & 0.0001 & 0.023 & 0.9 \\
\hline Aspartate transaminase & 0.41 & 0.0004 & -0.08 & 0.62 \\
\hline Alanine transaminase & 0.44 & 0.0002 & -0.03 & 0.84 \\
\hline Alkaline phosphatase & 0.46 & 0.0004 & -0.01 & 0.99 \\
\hline Prothrombin activity & -0.63 & 0.0001 & -0.14 & 0.37 \\
\hline Portal vein diameter & 0.19 & 0.3008 & -0.02 & 0.96 \\
\hline Splenic vein diameter & 0.24 & 0.147 & -0.32 & 0.16 \\
\hline Eosinophillic count & 0.41 & 0.0025 & 0.36 & 0.034 \\
\hline Haemoglobin & -0.33 & 0.0063 & -0.02 & 0.91 \\
\hline Leukocytes count & 0.12 & 0.92 & 0.087 & 0.59 \\
\hline
\end{tabular}

$r=$ correlation coefficient and $P=$ probabilities.

\section{DISCUSSION}

Eggs trapped in the liver lead to inflammation $^{(25)}$, collagen deposition and fibrous expansion of the portal spaces and intrahepatic portal-vein obstruction, a phenomena which may cause oesophageal varices ${ }^{(26)}$. The liver responds via regulated tissue regeneration to schistosomal injury as well as to its treatment. During every 
time of regeneration, there is histological changes ${ }^{(27)}$ and a major loss or regeneration of the hepatic tissue $^{(14)}$. Therefore, the effects of PZQ on one of the basement membrane component (LP1) and TBA were evaluated in the present study. Schistosomiasis mansoni infestation could overload hepatic injury on the basis of an already pathological situation. Hepatic schistosomiasis induces a compensatory hypertrophy of the hepatic artery, with increased sinusoidal pressure resulting in alterations of hepatic function ${ }^{(\mathbf{1 7})}$. This is already the case in the present study, since the LFTs were disturbed after bilharzial infestation (Tables 2 5). The disturbance in LFTs may be due to the entrapment of the bilharzia ova in hepatic tissues. Such entrapment causes inflammation around the ova, and therefore, activation of the lipocytes, hepatocytes and other collagen synthesizing cells (25) to increase their secretion of collagens and other components of extracellular matrix (ECM). The excessive secretion of ECM causes fibrous expansion and basement membrane formation with a subsequent liver damage. In the current study, the positive correlation between both LP1 and TBA individual levels with eosinophillic count confirms the above mechanism of fibrogenesis (Table 6).

Smerdson et al. ${ }^{(28)}$ showed that the increases in serum laminin levels are due to the formation of basement membranes in the hepatic sinusoids and may also be due to a lack of degradation of that protein by liver endothelial cells a mechanism which was supported by Arthur $^{(29)}$ who showed that, the increase in collagenolytic activity is a major mechanism of resolution of fibrosis. In addition, Zheng et al. ${ }^{(\mathbf{3 0})}$ showed that the increase in serum laminin concentration has been related to hepatic fibrosis and liver dysfunction in both human and experimental studies. This is already the case in the present study, because LP1 was strongly correlated with the markers of LFTs (Table 6).

David et $a .^{(31)}$ showed that human eosinophils can kill antibodycovered schistosomula. The killing mediated by eosinophils is associated with adherence of these cells and subsequent degranulation and release of the eosinophillic major basic protein onto the larvae. Therefore, the increase in the eosinophillic count in the blood of schistosomiasis, in the present study, may be one of the control mechanisms of the disease.

Silveira-Lemos et al. $^{(32)}$ studied the activation-related surface markers and the detection of tumor necrosis factor- $\alpha$ (TNF- $\alpha), \quad$ IL-4 and IL-5 markers in peripheral blood eosinophils from chronic Schistosoma mansoni infested patients. They pointed out, even patients with periportal fibrosis (PPF) presenting minor increment in eosinophil activation displayed higher levels of cytokine-positive eosinophils. They added that, lymphocyte-derived IL-10 was positively correlated with eosinophils cytokines, a finding which confirms the involvement of immunoregulatory mechanism in controlling disease morbidity in human Schistosomiasis. The increase in basement membrane formation and bile acid levels before PZQ,s 
treatment confirm the role of eosinophillia in the pathogenesis of the disease.

Moreover, the inflammation can activate the immune system cells causing excessive consumption of oxygen, increase in the amount of free radicals and decreases in the liver antioxidants' defences. All these consequences render the hepatocytes to undergo oxidative stress in the entire organ causing their damages ${ }^{(33)}$. Also, reports indicated that the redox cascade involved in maintenance of cell haemostasis, as well as in the parasitic protection against reactive oxygen species produced by the host is known to influence the prooxidantantioxidant balance in both host and parasite ${ }^{(\mathbf{1 0}, 33)}$. The final sequel of these events is a more increase in the deposition of ECM with subsequent liver derangement ${ }^{(9)}$. This may be another mechanism for liver fibrosis in schistosomiasis in this study.

Since hepatic schistosomiasis induces a compensatory hypertrophy of the hepatic artery with increased sinusoidal pressure resulting in alterations of hepatic function ${ }^{(17)}$, the improvement in the parameters of LFTs, the decrease in TBA and in LP1 mean levels after treatment with PZQ (Tables 2-5) confirm that of Zucoloto et al. $^{(34)}$ who showed that extensive schistosomal lesions do not hinder hepatic cell regeneration. Also, it confirms that of Friedenberg et al. ${ }^{(35)}$, who showed that the quantification of hepatic fibrosis is important to stage and follow up the progression of chronic liver diseases and that of Ebeid et al. ${ }^{(36)}$ who found that PZQ can be effectively used to treat $S$. haematobium infestation. In addition, the results of the present study confirm that of Botros et al. ${ }^{(37)}$ who showed that infection with $S$. haematobium became potent 73 days post infection (PI). Tissue egg load and worm fecundity were higher at 95 days and maximal at the $115^{\text {th }}$ post infection with an organ pattern comparable to that in schistosoma mansoni infection. They also added that, granuloma were similar to those of S. mansoni in the livers and urinary bladders and one hundred percent worm eradication was recorded with the higher dose of PZQ in animals treated 75 and 95 days post infection. This eradication may be the causative factors of LFTs improvement, the increase in the TBA levels and the reduction in the basement membrane formation with a resultant decrease in LP1 mean levels, in the present study. The elevation of LP1 levels during bilharzial infestation and the reduction of its levels after PZQ's treatment may confirm the role of LP1 in the regulation of inflammation. These confirm that of Adair-Kirk et al. ${ }^{(38)}$ who suggested that exposure of cryptic BM motifs at sites of injury may be an important mechanism for inducing expression of cytokines, expression and release of proteases, and recruitment of inflammatory cells. Together, these processes would serve to initiate repair and remodeling of the matrix and restoration of tissue integrity. This explanation is based on the improvement of LFTs, reduction in TBA and LP1 levels after PZQ treatment. Also, one can consider PZQ as a successful treatment of schistosomiasis. This is because Arthur ${ }^{(29)}$ indicated that, spontaneous 
resolution of liver fibrosis can occur after the successful treatment of the underlying disease or cessation of liver injury even if advanced fibrosis is present.

Abdel-Aziz et al. ${ }^{(39)}$ showed that, PZQ acts as schistosomicidal drug via its synergetic effect with the immune system through its effect on Th1 activation (elevation of IL-2 levels) in mice infested with $\mathrm{S}$. mansoni. The synergetic effect of PZQ with the immune system was also suggesred by Gryseels et al. ${ }^{(40)}$. Therefore, the status of the immune system must be taken into consideration during treatment of schistosomiasis with PZQ. In conclusion, PZQ is one of the drugs of choice to treat bilharziasis and both TBA and LP1 can be used together with the routine LFTs for monitoring and evaluation of the efficacy of response to such treatment. Also, the role of LP1 in the regulation of inflammation, in the initiation of the repair mechanisms and in remodelling of the matrix, and hence, restoration of tissue integrity must not be neglected.

\section{REFRENCES}

1- Farah, I.O., Mda, P.W., Kariuki, T.M., Nyindo, M.L, Blanton, R.E. and King, C.I. (2001): Repeated exposure induces periportal fibrosis in Schistosoma mansoni infected baboons: role of TGF- $\beta$ and IL4. J. Immunol., 164:5337- 5343.

2- Bica, I., Hamer, D.H. and Stacker, M.J. (2000): Hepatic schistosomiasis. Infect. Dis. Clin. N. Am., 14:583-604.

3- Tani, T., Lehto, V. P. and Virtanen, I. (1999): Expression of laminins 1 and 10 in carcinoma cells and comparison of their roles in cell adhesion. Exp. Cell Res., 248(7):115-121.

4- Walsh, K. M., Fletcher, A., MacSween, R. N. and Morris, A.J. (2000): Basement membrane peptides as markers of liver disease in chronic hepatitis C. J. Hepatol., 32(6):325-330.

5- Koutroubakis, I.E., Petinaki, E., Dimoulios, P., Vardas, E., Roussomoustakaki, M., Maniatis, A. N. and Kouroumalis, E. A. (2003): Serum laminin and collagen IV in inflammatory bowel disease. J. Clin. Pathol., 56:817-820.

6- Chiu, B.C. and Chonsue, S.W. (2002): Chemokine responses in schistosoma antigen-elicited granuli formation. Parasite Immunol., 24(6):285-94.

7- Loeffler, D.A., Lundy, S.K., Singh, K.P., Gerard, H.C., Hudson, A.P. and Boros, D.L. (2002): Soluble egg antigens from schistosoma mansoni induce angiogenesis-related processes by up-regulating vascular endothelial growth factor in human endothelial cells. J. Infect. Dis.; 185(11):1650-1656.

8- Hoffman, K,F., Wynn, T.A. and Dunne, D.W. (2002): Cytokinemediated response during Schistosoma infections, walking the fine line between immunological control and immunopathology. Adv. Parasitol., 52:265-307.

9- Abdallah, O.M., Hanna, S. dc., Reggi, $M$. and Gharib, $B$. (1999): Visualization of oxygen radical production in mouse liver in response to infection with 
Schistosoma mansoni. Liver 19(6):459-500.

10- Salazar-calderon, M., Martin Alonso, J.M., Ruiz de Equino, A.D. and Parra, F. (2005): Heterologous expression and functional characterization of thioredoxin from Fasciola hepatica. Parasitol. Res., 87(5):390-395.

11- Sarin, S.K. and Kapoor, D. (2002): Non-cirrhotic portal fibrosis: current concepts and management. J. Gastroenterol. Hepatol., 17(9):526-534.

12- Schiano, T.D., Kotler, D.P., Ferran, E. and Fiel, M.I. (2007): Hepatoportal sclerosis as a cause of noncirrhotic portal hypertension in patients with HIV. Am. J. Gastroenterol., 102:2536- 40.

13- Morikawa, H., Tamori, A. and Nishiguchi, S., et al. (2007): Expression of connective tissue growth factor in the human liver with idiopathic portal hypertension. Mol. Med., 13 (56):240-245.

14- Michalopoulos, G.K. and DeFrances, M. (2005): Liver regeneration. Adv. Biochem. Eng. Biotechnol., 93: 101-134.

15- Ohmae, H., Tanaka, M., Hayashi, M., Matsuzaki, Y., Kurosaki, Y., Blas, B.L., Portillo, G.G., Sy, O.S., Irie, Y. and Yasuraoka, K. (1992): Ultrasonographic and serologic abnormalities in Schistosoma japonicum infection in Leyte, the Philippines. Am. J. Trop. Med. Hyg., 46(1):89-98.

16- Bo Angelin (2005): Telling the liver (not) to make bile acids: a new voice from the gut? Cell metabolism 2 (4): 209-210.
17- Andrade, Z.A. (1986): Liver sinusoidal pathology and schistosomiasis. Rev. Soc. Bras. Med. Trop., 19: 63-65.

18- Costa, G., Cunha-Melo, J.R., Aguiar, B.G., Goncalves, S.C., Toppa, N.H. and Coelho, P.M. (1999): Hepatic regeneration after partial hepatectomy in mice infected with Schistosoma mansoni, at the acute and chronic phases of the disease. Rev. Inst. Med. Trop. (São. Paulo), 41: 255258.

19- Bataller, R. and Brenner, D.A. (2005): Liver fibrosis. Clin. Invest., 115 (2): 209-218.

20- Katz, N., Chaves, A. and Pellegrino, J.A. (1970): Simple device of quantitative stool thick smear technique in Schistosoma mansoni. Rev. Inst. Med.Trop. (Sao Paulo), 14: 397- 400.

21- Block, C.A. and Wathins, J.B. (1978): Determination of conjugated bile acids in human bile and duodenal fluid by reverse phase high performance liquid chromatography. J. Lip. Res., 19:510-513.

22- Bartles, H. and Bohmer, A. (1970): Simple method for bilirubin determination. Clin. Chem., 7:444-446.

23- Kind, P.R.N. and King, K.S. (1954): Estimation of plasma phosphatases by determination of hydrolyzed phenol by amino antipyrine. J. Clin. Pathol., 7:322326.

24- Reitman, S. and Frankel, S.A. (1957): Colorimetric method for determination of serum transaminase activity. Am. J. Clin. Pathol., 28:56-60.

25- Cheever, A.W., Lenzi, J.A., Lenzi, H.L. and Andrade, Z.A. 
(2002): Experimental models of Schistosoma mansoni infection. Mem. Inst. Oswaldo. Cruz., 97: 917-940.

26- Abath, F.G., Morais, C.N., Montenegro, C.E., Wynn, T.A. and Montenegro, S.M. (2006): Immunopathogenic mechanisms in schistosomiasis: what can be learnt from human studies? Trends Parasitol., 22: 85-91.

27- Baptista, A.P. and Andrade, Z.A. (2005). Angiogenesis and schistosomal granuloma formation. Mem Inst Oswaldo Cruz 100: 183-185.

28- Smerdson, B., Paulsson, M. and Johansson, S. (1989). Uptake and degradation in vivo and in vitro of laminin and nidogen by rat liver cells. Biochemical Journal 261: 37-42.

29- Arthur, M.J.

(2002): Reversibility of liver fibrosis and cirrhosis following treatment for hepatitis C. Gastroenterology 122:1525-1528.

30- Zheng, M., Cai, W., Weng, H. and Liu, R. (2003): Determination of serum fibrosis indexes in patients with chronic hepatitis and its significance. Chinese Medical Journal 116: 346-349.

31- David, J. R., Butterworth, A. E. and Vadas, M.A. (1980): Mechanism of the Interaction Mediating Killing of Schistosoma mansoni by Human Eosinophils. Am. J. Trop. Med. Hyg., 29(5), :842-848

32- Silveira-Lemos, D., TeixeiraCarvalho, A., Martins-Filho, $O$. A., Oliveira, L. A., Costa-Silva, M.F., Matoso, L.F., de Souza, L.J., Gazzinelli, A. and CorrêaOliveira, R. (2008): Eosinophil activation status, cytokines and liver fibrosis in Schistosoma mansoni infected patients. Acta Tropica 108 (2-3): 150-159.

33- Wagih, A., Sheta, E. and Ismail, H. (2007): Effects of fasciolisis and schistosomiasis mansoni on the anti-oxidant defense mechanisms. Tanta Medical Sciences' Journal 2 (2):56-66.

34- Zucoloto, S. da Silva, J.C., de Castro e Silva Junior, O., Ganzaga, E.Z. and Dal Fabbro, A.L., (1990): Hepatic regeneration after hepatectomy in schistosomatic fibrosis. Int. J. Exp. Pathol., 71:465-468.

35- Friedenberg, M.A., Miller, L., Chung, C.Y., Fleszler, F., Banson, F.L., Thomas, R., Swartz, K.P. and Friedenberg, F.K. (2005): Simplified method of hepatic fibrosis quantification: design of a new morphometric analysis application. Liver Int., 25: 1156-1161.

36- Ebeid, F.A., Mahmoud, S.S., Botros, S.S. and Badawy, A.A. (2005): Evaluation of the antibilharzial activity of mirazid versus praziquantel against $\mathrm{S}$. haematobium: An experimental study. Egyptian Journal of Schistosomiasis and Infectious Endemic Diseases 27:25-37.

37- Botros, S.S., Hammam, O.A., El-Lakkany, N.M., Seif el-Din, S.H. and Ebeid, F.A. (2008): Schistosoma haematobium (Egyptian Strain): Rate of Development and Effect of Praziquantel Treatment. Journal of Parasitology 94(2):386-394.

38- Adair-Kirk, T. L., Atkinson, J. J., Kelley, D.G., Arch, R.H. and Senior, R.M. (2005): Chemotactic Peptide from 
Laminin 5 Functions as a Regulator of Inflammatory Immune Responses via TNFmediated Signalling. The Journal of Immunology 174:1621-1629.

39- Abdel-Aziz, M.M., Abbas, A.T., Elbakry, K.A., Toson, E.A. and El-Sherbini, M. (2006): Immune response in mice infected with Schistosoma mansoni and treated with Myrrh. J. Med. Sc., 6 (5): 858-861.

40- Gryseels, B., Stelma, F.F. and

Talla, I., et al. (1994): Epidemiology, immunology and chemotherapy of Schistosoma mansoni infection in a recently exposed community in Senegal. Am. J. Trop. Med. Hyg., 56: 511514.

\title{
تأثثير العلاج بالبرازكوانتيل على مستوى أحماض الصفراء وتكوين الغشاء

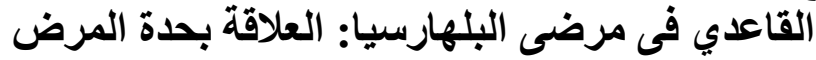

\author{
* الثحات أبو مسلم طوسون و** قدري جاد

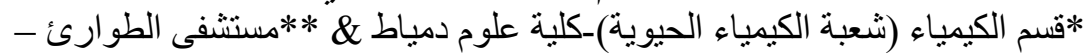

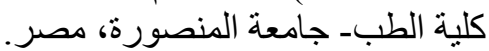

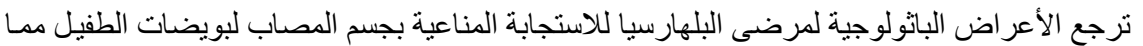

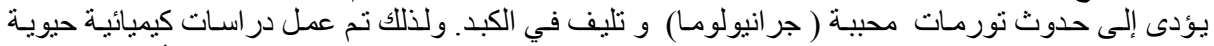

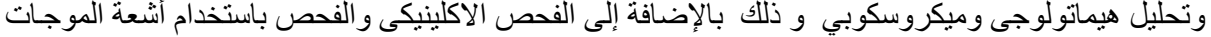

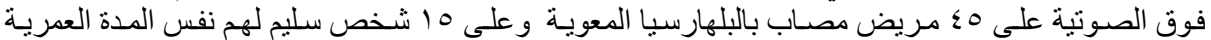

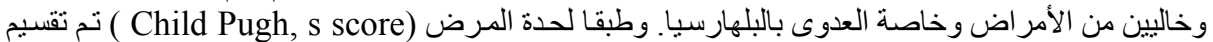

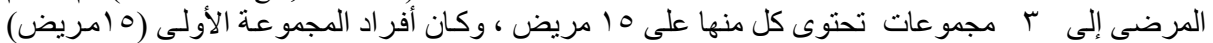

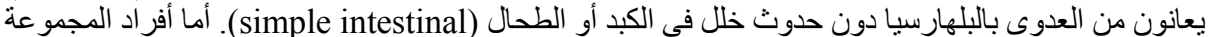

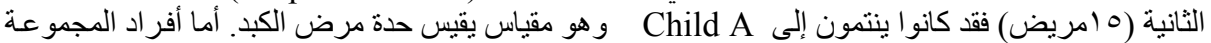

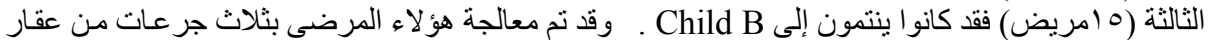

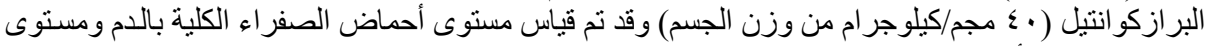

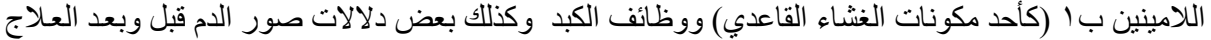

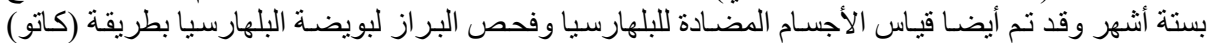

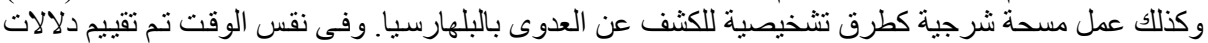

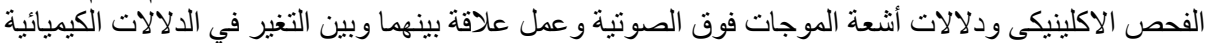

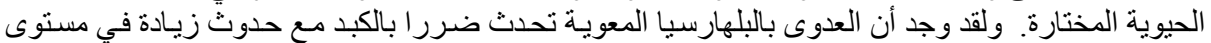

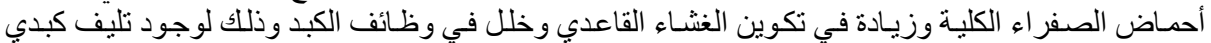

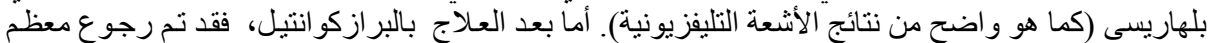

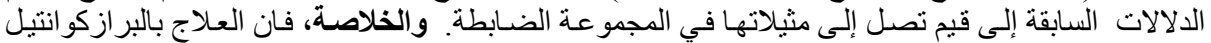

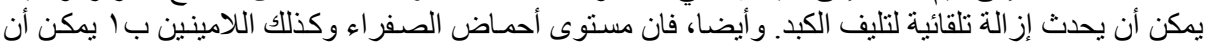

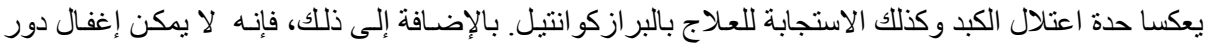

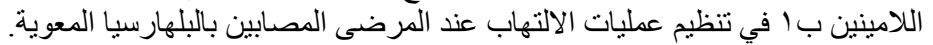

